\title{
MELHORIA DA EFICIÊNCIA REPRODUTIVA PELO ACOMPANHAMENTO DO PUERPÉRIO EM BOVINOS LEITEIROS (dados parciais)
}

\section{ROCHA $^{1}$; L.E. KOZICKI ${ }^{2}$}

${ }^{1}$ Curso de Pós Graduação em Ciências Veterinárias da Universidade Federal do Paraná. ${ }^{2}$ Professor - Departamento de Medicina Veterinária, Setor de Ciências Agrárias da Universidade Federal do Paraná.

O trabalho teve por objetivo melhorar a eficiência reprodutiva de vacas leiteiras, através de acompanhamento clínico do puerpério. Os animais eram da raça holandesa preta e branca, com escore da condição corporal (ao $1^{\circ}$ exame) variando entre 2,5 a 4,0 e submetidas a inseminações artificiais (IA), produzindo em média vinte litros de leite por dia. A alimentação baseou-se em forrageiras tais como o capim napier e tanzânia, silagem de milho e o concentrado fornecido aos animais por produtividade. Sistematicamente, as vacas eram examinadas quinzenalmente após o parto (fisiológico ou patológico) mediante exame de toque retal (verificação da espessura, simetria e contratilidade uterina) e vaginoscópio (forma, abertura, coloração, umidade de mucosa cérvicovaginal e tipo de muco) até que a genitália estivesse involuída e capaz de conduzir nova gestação. Em torno da $8^{\mathrm{a}}$ semana de puerpério, os animais eram liberados para a realização da IA, caso a genitália estivesse em ótimas condições ou permaneciam em tratamento até o final do processo infeccioso. As vacas com problemas de retenção de placenta, endometrite ou outras afecções eram devidamente tratadas com a antibioticoterapia intra-uterina convencional. No total, estudou-se 44 vacas sendo que 32 destas foram acompanhadas por duas ou mais gestações consecutivas. A média do número de partos atingiu a $2,4 \pm 1,2$. A primeira visita veterinária ocorreu no 9,3 $\pm 6.1^{\circ}$ dia. Os demais resultados encontram-se na Tabela 1.

Tabela 1. Alguns parâmetros reprodutivos obtidos de vacas holandesa preta e branca pelo acompanhamento ginecológico no puerpério, na Região Centro-Oeste do Estado do Paraná. ( $\mathrm{n}=44), 1994$ - 1997.

\begin{tabular}{|c|c|c|c|c|c|c|c|}
\hline $\begin{array}{l}\text { Ocorrência } \\
\text { de ovulação } \\
(\%)\end{array}$ & $\begin{array}{l}\text { Achados uterinos }{ }^{1} \\
\text { liberação p/IA } \\
\text { (dias) }(\%)\end{array}$ & $\begin{array}{c}\mathrm{N}^{\mathrm{o}} \\
\text { tratamentos } \\
\text { para cura } \\
(\mathrm{dias})(\%)\end{array}$ & $\begin{array}{l}\text { Intervalo } \\
\text { parto/ } \\
\text { prenhez } \\
(\mathrm{x} \pm \mathrm{s})\end{array}$ & $\begin{array}{l}\text { Intervalo } \\
\text { parto/ } 1^{\mathrm{a}} \\
\text { prenhez } \\
(\mathrm{x} \pm \mathrm{s})\end{array}$ & $\begin{array}{l}\text { Intervalo IA } \\
\text { parto/ }(x \pm s)\end{array}$ & $\mathrm{N}^{\circ} \mathrm{IA}(\mathrm{x} \pm \mathrm{s})$ & $\begin{array}{c}\text { Taxa de } \\
\text { prenhez }(\%)\end{array}$ \\
\hline $\begin{array}{l}\mathrm{OE}=23,0^{\mathrm{a}} \\
\mathrm{OD}=41,0^{\mathrm{b}}\end{array}$ & $\begin{array}{c}\text { End } \mathrm{I}^{\circ} \text { grau }=31,4 \\
\text { End.II }{ }^{\circ} \text { grau }=5,6 \\
\text { End.III }{ }^{\circ} \text { grau }=16,8 \\
\text { Sem Endom }=46,2\end{array}$ & $\begin{array}{c}1 \operatorname{trat}^{\mathrm{O}}=87,2 \\
2 \operatorname{trat}^{\mathrm{os}}=10,6 \\
3 \operatorname{trat}^{0 \mathrm{~s}}=4,2\end{array}$ & $59,0 \pm 15,6$ & $90,4 \pm 29,7$ & $109,8 \pm 31,4$ & $1,5 \pm 1,2$ & 92,9 \\
\hline
\end{tabular}

Legenda: $1=$ até que os animais fossem liberados pelo profissional.; $\mathrm{OE}=$ ovário esquerdo; $\mathrm{OD}=$ ovário direito; $\mathrm{CL}=\mathrm{corpo}$ lúteo. $\mathrm{a}: \mathrm{b}=\mathrm{p}<0,05$

Durante os estudos foi possível acompanhar 32 animais, dentre os quais, alguns pariram até 3 vezes. Considerando-se somente os animais acompanhados em dois partos sucessivos e puerpério subsequente, verificou-se que $31,2 \%, 18,7 \%, 18,7 \%$ e $31,2 \%$ tiveram respectivamente endometrite após o $1^{\circ}$ e $2^{\circ}$ parto, endometrite somente após o $1^{\circ}$ parto, endometrite somente após o $2^{\circ}$ parto e não tiveram problema algum. Levando-se em consideração a cifra obtida no primeiro grupo, tornou-se possível ligar as sucessivas endometrites, dentre outras causas, à débil constituição hereditária desses animais frente às infecções, recomendando-se o seu afastamento da reprodução. Os resultados permitem concluir que o ovário localizado no lado direito foi significativamente mais ativo tendo em vista o percentual de ovulações ocorrido; que os índices de endometrite em seus três níveis foi bastante elevado atingindo $53,8 \%$. Tais achados sugerem a existência de deficiente higiene do parto, excessivas intervenções partais por pessoal não habilitado, retentio secundinarum e nutrição desequilibrada, elevando consequentemente a cifra de afecções; que a antibioticoterapia intra-uterina conduzida demonstrou ser eficiente em todos os graus, salientando-se que $87,2 \%$ dos animais tiveram o endométrio livre de infecção com um único tratamento. Este fato sinaliza a eficiência dos antibióticos intra-uterinos utilizados, confrontando-se com algumas tendências de que não se deve tratar endometrite intrauterinamente. $\mathrm{O}$ acompanhamento do decurso do puerpério, embora por exames clínicos rotineiros, demonstrou ser prática eficiente ao tornar disponíveis os animais a novo processo reprodutivo; que embora a primeira IA tenha sido efetuada em torno do $90^{\circ}$ dia p.p., elevado percentual dos animais encontrava-se em gestação no $110^{\circ}$ dia; que a cifra de 1,5 serviços por prenhez encontra-se de acordo com a literatura; que animais bem conduzidos e acompanhados durante o puerpério precoce e clínico são capazes de responder com elevado percentual de gestação. A boa condução do puerpério acarreta ganhos aos produtores na produção de leite, na redução do número de serviços/concepção e na diminuição do intervalo entre partos de vacas. 